\title{
Molino de Llovera, patrimonio de la arquitectura tradicional de la Huerta de Valencia
}

\author{
Carmen Cárcel-García, Pedro Verdejo Gimeno y David Clemente Ramírez \\ Universitat Politécnica de Valencia \\ carcel@ega.upv.es, pedvergi@,ega.upv.es
}

\begin{abstract}
Resumen. De todo el sistema de huertas que conforman la Comunidad Valenciana: huertas de la Plana de Castelló, el Camp de Morvedre, la huerta de Xátiva, la Ribera del Xúquer, la Plana de Gandía... Vamos a centrarnos en la propia huerta de Valencia, aquélla que se reconoce como Huerta Histórica, puesto que además de despuntar como la más significativa de las huertas, debido a su antigüedad y su complejo sistema de riego ${ }^{1}$, es el enclave geográfico donde se asienta Campanar. Esta población, al igual que otros asentamientos de la huerta, se desarrollaba como arrabal a las afueras de la ciudad. El origen de estos núcleos islámicos es difícil de descifrar ya que son escasos los documentos que sobre éstos se conservan. En cambio, sí que existen escritos que documentan el paisaje de regadío que envolvía estos enclaves: estructura de riego, molinos, alquerías, huertos, casas rurales, etc..
\end{abstract}

Palabras clave: Huerta, patrimonio, recuperación.

\begin{abstract}
The whole system of gardens that make Valencia: orchards of Castelló de la Plana, the Camp of Morvedre, Orchard Xativa, Ribera del Xuquer, Plana de Gandia ... Let's focus on the very garden of Valencia, it Huerta is recognized as Historic, since in addition to stand out as the most significant of the orchards, due to its age and its complex irrigation system, is the geographical location where it sits Campanar. This population, like other settlements in the garden, developed as suburbs on the outskirts of the city. The origin of these Islamic centers is hard to decipher and that few of these documents are preserved. However, yes that written documenting the landscape irrigation that enveloped these enclaves: structure irrigation, mills, farms, orchards, farmhouses, etc.
\end{abstract}

Keywords: Huerta, heritage, recovery.

\section{Introducción}

A partir del siglo XX las ciudades desbordadas por el aumento de la natalidad y/o por el éxodo rural comenzarán a extenderse hacia su periferia con un crecimiento rápido y descontrolado, donde las alteraciones en el paisaje tradicional alcanzaran niveles de transformación impensables en otros tiempos, que han llevado a la destrucción de la identidad de estos hábitats rurales. Las fértiles huertas de regadío, como el caso de la Huerta Histórica de Valencia ${ }^{1}$, que por siglos se habían mantenido intactas comenzaron a peligrar, siendo un sujeto pasivo de este crecimiento incontrolado que arrasó las tierras de regadío más próximas a las ciudades con sus históricos asentamientos agrícolas y pre-industriales.

Si nos centramos en el caso particular de Valencia, nadie cuestiona la deuda histórica que la ciudad de Valencia tiene con su Huerta y sus poblados periféricos: pequeñas poblaciones que llegaron a tener autonomía propia y que han visto menguar su identidad al mismo ritmo que desaparecía su entorno rural, llegando literalmente a ser absorbidas por el fenómeno de la gran urbe.

\footnotetext{
1 Sistema de riego complejo formado por doce comunidades de regantes con diferentes características y competencias, y ocho sistemas hidráulicos, siete de los cuales forman el Tribunal de las Aguas de Valencia: acequias de Rovella, Favara, Mislata-Xirivella, Quart-Benàger-Faitanar, Tormos, Rascanya y Mestalla; y el octavo, la Real Acequia de Moncada.
} 
La Huerta y los asentamientos rurales periurbanos resultaron esenciales para el crecimiento y desarrollo económico de la ciudad desde prácticamente los orígenes de la misma. Se trataba de una relación necesaria, fundada en el respeto entre las partes. La entrada en el siglo XX trajo consigo la revolución industrial y el consiguiente crecimiento de la ciudad, exponentes máximos de la modernidad y oponentes claros de la tradición. La huerta y su ámbito rural perderán su papel protagonista para formar parte del segundo plano de la realidad social. Ello supondrá la hegemonía de la ciudad sobre la huerta, la modernidad sobre lo tradicional, en definitiva, el crecimiento anárquico e irreflexivo de una ciudad sobre su huerta.

Centrando el estudio sobre la antigua población de Campanar, al igual que otros núcleos periféricos, sufrirá este fenómeno de trasgresión urbanística y pasará a formar parte, como un barrio más, del tejido urbano de la ciudad. La ejecución del planeamiento, en este caso, se llevó a cabo de forma lenta y caótica, exceptuando el caso particular del Pouet, histórica partida situada en plena huerta de Campanar, cuya actuación se demorará hasta finales del siglo XX, pero su intervención será rápida y devastadora (Teixidor, 1982).

Se abren grandes vías de comunicación de la ciudad con el extrarradio que fraccionan completamente el territorio de esta parte de huerta, como la avenida de Campanar, la Avda Pio XII, la Avenida General Avilés o la Avenida Maestro Rodrigo, verdaderas barreras que aíslan y subdividen este extenso territorio. Hoy subdividido en cuatro barrios: Campanar, Les Tendetes, El Calvari y Sant Pau, síntesis de una realidad histórica de partidas rurales que conformaban el paisaje tradicional de esta población: Dalt, Pouet, l’Horta, D’Enmig, Campanar pueblo, Sant Pau, Vora Riu, Tendetes o el Calvari, entre otras. La mayoría de ellas sucumbieron ante la construcción de bloques residenciales de viviendas e instalaciones hospitalarias, comerciales y educacionales, a destacar el hospital la Fe, el centro comercial Nuevo Centro y la Consellería de Educación.

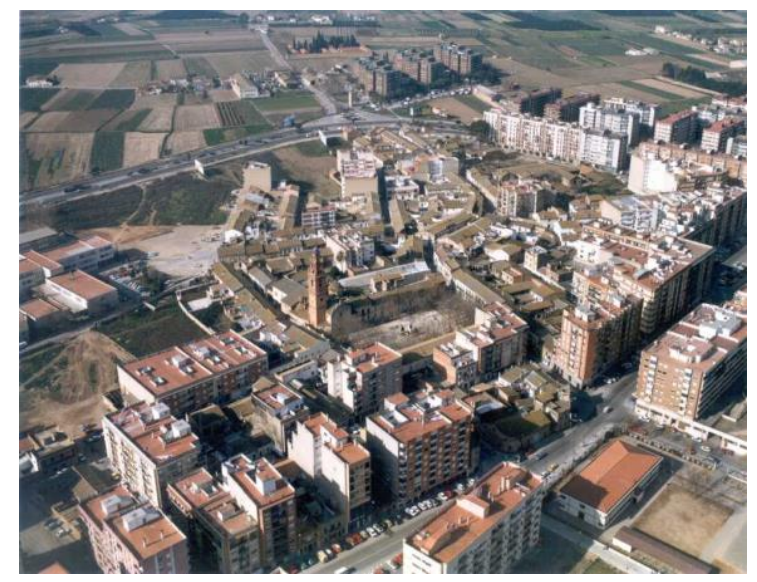

Fig. 1. Vista aérea de la población de Campanar en la década de 1990.

Es importante destacar que, de todas ellas, únicamente queda medianamente indemne la partida de Dalt y el núcleo antiguo ${ }^{2}$ de Campanar, gracias a diversos planes de protección

\footnotetext{
${ }^{2}$ El núcleo tradicional de Campanar se ha mantenido gracias a leyes de protección que se hicieron efectivas a partir del PGOUV de 1988 y que, como el Plan Especial del Entorno BIC de 2010, siguen manteniendo la protección sobre su paisaje urbano.
} 
que en ambos casos han evitado que corriesen la misma suerte que el resto de partidas, hoy en día desaparecidas.

Tras conocer la realidad en la que se encuentra actualmente nuestra Huerta, paisaje histórico tradicional, personalizada en el caso concreto de Campanar, donde las pocas pervivencias patrimoniales que han subsistido, bajo la inercia de un proceso urbanístico especulativo e interesado, se debaten entre la desidia y el abandono, y siendo conscientes de la pérdida de las señas de identidad de estos enclaves históricos y la desvinculación completa de la huerta con la ciudad, apostamos por trabajar en favor de la recuperación de los valores perdidos.

La Huerta Histórica y su sistema hidráulico de riego, los artefactos molineros, las alquerías, los núcleos concentrados, etc. son ejemplos de un patrimonio, que al contrario de las grandes manifestaciones patrimoniales, son el reflejo de la cotidianidad de la sociedad. Es evidente que el gran valor que tiene este patrimonio no es artístico sino, más bien, histórico y cultural. Por lo tanto, salvaguardarlo ayudará a recuperar la memoria del paisaje histórico tradicional de la Huerta de Valencia.

A partir de este planteamiento base surge hace tres años un Proyecto de Colaboración Universidad - Ciudad, suscrito entre el Ayuntamiento de Valencia, la Universidad Politécnica y las Asociaciones de Vecinos, desarrollado por profesores de la Escuela Técnica Superior de Ingeniería de la Edificación (ETSIE). Este proyecto tiene como objetivo la puesta en valor del Patrimonio Arquitectónico Menor de la ciudad de Valencia, particularizado en el caso que nos ocupa, Campanar. Se trata pues, de potenciar la investigación universitaria y sus recursos humanos en pos del conocimiento y divulgación de la riqueza de dicho patrimonio y, consecuentemente de salvaguardar las señas de identidad de un parte de ciudad que conforma el paisaje histórico de la Huerta de Valencia.

El proyecto se lleva a cabo en dos fases: de conocimiento y de divulgación. En la primera fase, alumnos de Proyecto Final de Grado de la ETSIE, realizan el levantamiento gráfico de casas y alquerías de Campanar, brindadas de manera altruista por los propietarios de las mismas. El levantamiento y conocimiento exhaustivo de los inmuebles por parte de los alumnos, les brinda la oportunidad de valorar la riqueza de este patrimonio y adquirir la conciencia y sensibilidad necesarias que requiere trabajar con estas arquitecturas de valor incuestionable.

En la segunda fase, los profesores con la ayuda inestimable de los alumnos involucrados al $100 \%$, desarrollan la etapa de divulgación en colaboración con las Instituciones Públicas donde se pretende hacer extensible este conocimiento al resto de la sociedad, aportando el conocimiento adquirido a favor de un cambio en la conciencia ciudadana y administrativa, que conlleven el respeto, la conservación y la puesta en valor de una parte de nuestra historia. 


\title{
2 Los elementos estructurales que caracterizan el paisaje de regadío de la Hueta Histórica de Valencia.
}

\begin{abstract}
"Hemos llegado por último al país mas rico, mejor cultivado y sin duda ninguna el mas interesante de la peninsula. Cuantos lo han visitado y descrito nos presentan la vega de $V$ alencia como un inmenso jardín, que contine en si toda especie de cultivo y de produciones. Pero em medio de estas riquezas agrícolas, en este paraíso de algunos poetas nacionales, lo que llama mas la atención del agrónomo, es este admirable sistema de riego que parece haber resistido á los siglos, sin sufrir la mas leve alteración."
\end{abstract}

F. Jaubert de Passá (1844, pp.134)

A lo largo del tiempo el paisaje de la huerta ha acompañado a la ciudad de Valencia, siendo parte de su propia identidad. No es una característica que no compartan otras ciudades a lo largo de la cuenca Mediterránea y en otras partes del mundo, pero la peculiaridad de esta huerta radica en una "compleja interrelación entre la ordenación del territorio....., el establecimiento de la red de poblamiento, las vías de circulación y la estructura de los parcelarios de las tierras de cultivo" (Guinot, 2007, pp. 60), que no es apreciable en otros lugares que comparten el mismo paisaje agrario.

Como es de suponer debido a su proximidad a la ciudad, la Huerta de Valencia ha sufrido su influencia inmediata desde prácticamente sus orígenes, siendo una de las zonas de mayor ocupación durante siglos y de intensa explotación económica, tanto agrícola, ganadera e industrial. Tal y como apunta, Enric Guinot (2007, pg. 60-98):

"(...) en su escenario geográfico se han producido y han influido todos los gran-des cambios en la organización social, política y económica del mundo musulmán, del mundo feudal bajo-medieval, del mundo de las monarquias absolutas de la época Moderna, de la revolución burguesa y de la modernización contemporánea. No bay que olvidar que todos estos cambios bistóricos nos proporcionan diferentes visiones de una buerta viva, cuya fisonomia ba ido tomando forma a partir de la superposición de sucesivas capas cuya imprenta marcada sobre el territorio está, en muchos casos, aún por determinar".

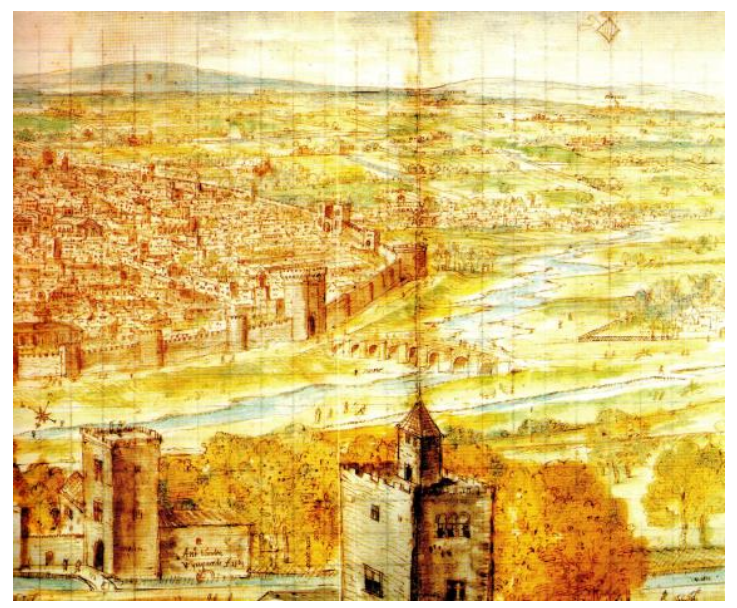

Fig. 2. Detalle de la ciudad de Valencia y su huerta en el plano d'Anthonie van der Wijngaerde, 1563, (Rosselló, 1990) 


\subsection{E1 sistema de regadío. Las acequias de Campanar.}

En la Huerta de Valencia el sistema hidráulico sigue el modelo característico de captación de agua mediante los azudes o presas del río Turia, el canal principal o acequia madre y la red

de canales que distribuyen el agua por las tierras, brazos, filas, rolls,...etc. El desarrollo de este sistema de riego y su implantación en el paisaje adecuándose a las curvas de nivel, generaron un aprovechamiento respetuoso del territorio. Además, la existencia de un número tan abundante de casals obligaba a un sistema de repartición del agua más complejo, puesto que el canal principal no sólo suministra agua a una huerta sino a varias. Este sistema de distribución equitativa de las aguas se llevaba a cabo mediante un repartidor de lengua.

El río Turia riega la fértil llanura valenciana, derramando sus aguas por todo su territorio distribuyéndola por acequias hasta un total de 31 canales. En 1617, el fiscal Melchor Cisternes, ya elaboró una relación de 20 acequias entre Terrabaixa y Pedralva (Jaubert, 1844) que formaban parte del vasto sistema de riego de este caudaloso rio al que pertenecían, además, las acequias de Villamarxant, Benaguasil y Riba-roja, y las ocho últimas derivaciones encargadas de regar la Huerta Histórica de Valencia.

Centrándonos en la Huerta Histórica, que es la que nos interesa, nos encontramos con un espacio irrigado de gran valor, caracterizado tanto por su antigüedad como por su complejidad organizativa, concentrada en ocho sistemas hidráulicos - las acequias que constituyen el Tribunal de las Aguas (Rovella, Favara, Mislata-Xirivella, Quart-Benàger-Faitanar, Tormos, Rascanya y Mestalla) y la Real Acequia de Moncada -.

Estos antiguos espacios irrigados estaban perfectamente diseñados, no dejando nada a la casualidad, así podemos observar el sinuoso trazado de las acequias adaptándose al terreno para una mejor circulación y aprovechamiento del agua, la ubicación específica de las residencias agrarias en la parte alta de la acequia para regar la mayor superficie de la parcela o la localización estratégica de los molinos en los puntos donde se producían los saltos de cota de las acequias (Guinot, 2007, p.70) y no perjudicará gravemente a los regantes.

De estas ocho últimas derivaciones vamos a fijar nuestro interés en aquellas acequias que irrigan la Huerta Norte, donde se ubica Campanar, es decir, Tormo, Mestalla y Rascanya.

La acequia de Tormos es la primera del conjunto de las acequias que coge agua por la parte izquierda del rio, siendo la más próxima a la acequia Real de Moncada. Su espacio de riego comprende los términos de Benimàmet, Beniferri, Benitaha, Benicalap, Borbotó, Carpesa y parte de Paterna, Burjassot, Quart de Poblet y por supuesto, Campanar. Esta extensa superficie de huerta era regada mediante la diversidad de brazos, filas y rolls que facilitaban las labores de repartición del agua.

Esta acequia riega una amplia área de Campanar, desde l'Horta Nord hasta Beniferri. Parte de esta huerta está regada por la fila de Campanar, uno de los brazos más importantes y antiguos, de época medieval. Esta huerta situada al norte de Campanar, en la partida de Dalt, es el único espacio de regadío que hoy en día está activo en esta zona. El resto de huerta, perteneciente históricamente a los términos de Beniferri y Benimámet, es regada por varios rolls entre los que destaca el antiguo Tragador. 


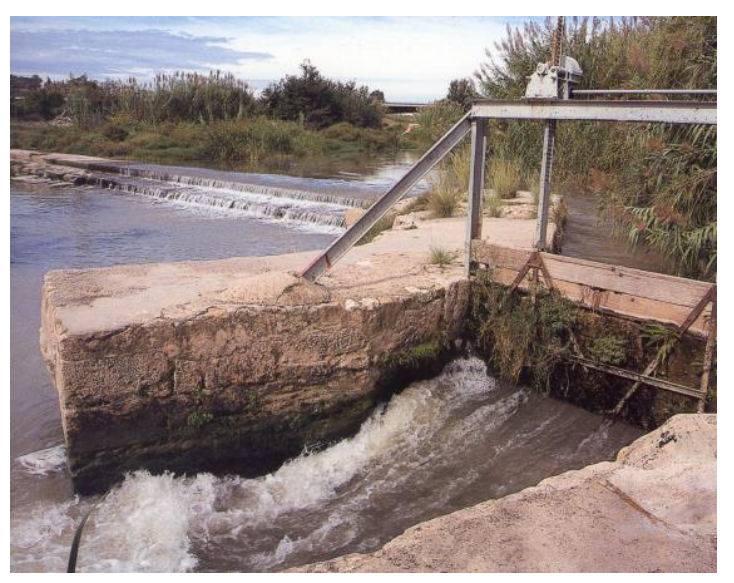

Fig. 3. Partidor en funcionamiento de la Acequia de Tormos, (Guinot y Selma, 2005, p. 166).

La huerta de Campanar era regada casi en su totalidad por la acequia de Mestalla, particularmente por el brac de Petra y sus derivaciones, el bracet del Ponet que regaba la parte meridional y el bracet de Batle y la fila del moli d'Horta que regaban la parte septentrional. Para hacerse una idea, en 1815 la huerta histórica de Campanar representaba un 42\% del riego total de la acequia. Hoy en día, todas estas zonas de riego han desaparecido quitando parte de la partida de Dalt que aún se mantiene protegida de la especulación urbanística.

Las primeras llengües son las de Mestalla-Petra, trascendentales ya que parten el agua en tres tercios, uno para Petra y dos para la acequia madre. Se sitúan en la huerta de Campanar, después del molino Nou y antes de llegar al molino Llovera.

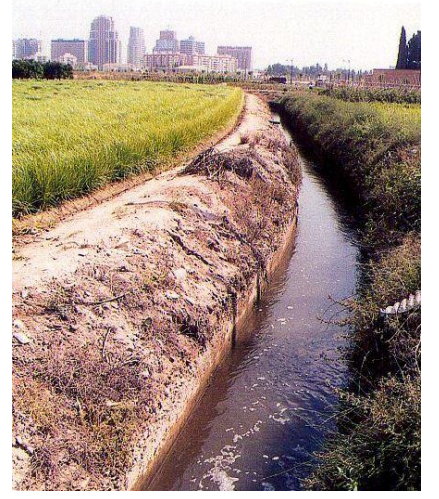

Fig. 4. Brazo de Petra, a su paso por detrás del cementerio de Campanar. (Guinot y Selma, 2005, p. 51)

Según documentación consultada, el tramo inicial de la acequia de Petra tenía reducida la función de riego, en sus orígenes, sirviendo exclusivamente al entorno de Campanar y el molino del Comte o Ponça, aunque posteriormente se va a ampliar su cometido diversificándose en varios ramales o brazos. El braç d'enmig atravesaba la pequeña población hasta llegar al molino d'Orellana. El braç del Pouet partía del partidor del molino del Comte y se extendía hacia el sur regando toda la huerta del Pouet, uno de los espacios de riego con mayor extensión y más antiguos de Campanar, puesto que ya estaba organizada en época medieval. Por último el brazo principal de Petra que, a la altura del partidor de Ponça, ha- 
cía un giro próximo a los 90 grados dirigiéndose en dirección noreste hasta el cruce con la acequia madre de Mestalla, próximo al molino d'Horta. Este extenso tramo de huerta situado en la parte más oriental era regado por la acequia de Petra junto con los brazos de Batle y del molino d'Horta.

La acequia de Rascaña es el sistema más próximo al rio Turia y el último en recoger agua por la parte izquierda. Sus orígenes son islámicos ${ }^{3} \mathrm{y}$, parece ser, que con el objeto de su construcción se pretendía dar servicio a las huertas situadas más al norte, antiguas alquerías d'Orriols, Rascanya/convent de San Miguel dels Reis, Tavernes Blanques, Alboraia y Almàssera, entre otras, así lo atestigua el escaso riego que la acequia aportaba a la huerta de Campanar ${ }^{4}$, Tendetes y Marjalenes a pesar de atravesar su territorio. Sin embargo el copioso caudal de la acequia madre en esta primera etapa de recorrido fue aprovechado para instalar importantes artefactos hidráulicos durante esta primera época inicial (Mangue, 2001, pp. 101). Con el tiempo se aumentará su superficie de riego, específicamente en la zona comprendida entre Campanar ${ }^{5}$ y la primera gran derivación, el braç de Guatla, situado justo en el cruce de éste con la acequia de Moncada, tierras regadas seguramente con anterioridad por la acequia de Mestalla. Aunque estas nuevas parcelas de huerta no supondrán más que un $8 \%$ del total de hanegadas regadas por la acequia.

A partir de molino Nou, primer artefacto ubicado sobre el cajero de esta acequia, y antes de llegar al siguiente molino del Sant Pau, se encontraban las primeras derivaciones para regar la huerta de Campanar, en especial la fila de Sant Pau que regaba una amplia zona hasta llegar al rio y próxima al puente de la avenida de Fernando el Católico. A continuación y llegando al molino de la Torreta, regaba la huerta de Tendetes ayudada por diferentes filas, resaltando las de Sant Miquel y Recaredo o Recadero. Finalmente, con un trazado en forma de "S" regaba la zona más alta conformada por Marjalenes y Benicalap.

\subsection{La red de caminos.}

A partir del siglo XIII se tiene constancia de la existencia de una red definida de caminos principales, radiales a partir del centro urbano llamados els camins reials. En el plano de Jaubert de Passá (1820), podemos apreciar esta red y su configuración radial desde su origen, la ciudad, a las distintas poblaciones periféricas. Como es obvio, este sistema viario estaba a su vez conformado por travesías, sendas y caminos secundarios que comunicaban las poblaciones periféricas entre sí o, sencillamente vinculaban los múltiples asentamientos aislados de la huerta.

Con el desarrollo evolutivo registrado a partir del siglo XIX, esta red de caminos principales y secundarios, empezó a ser destruida por la construcción de nuevas infraestructuras viarias que invadieron la huerta y fracturaron el antiguo sistema viario. Estos caminos forales que habían permanecido inalterables a lo largo del tiempo se convirtieron en vías de segundo orden, en los conocidos Camins Vells (Guinot, 2007). El caso particular de Campanar no será una excepción, su término será invadido por nuevas infraestructuras viarias de

\footnotetext{
${ }^{3}$ Según Borrull (1851) el mismo Abderrahman mandó a su hijo construir la acequia de Rascaña, con posterioridad a las de Mestalla y Tormo.

4 "el término de Campanar riega de la acequia de Rascaña trescientas setenta y ocho hanegadas de tierra buerta" texto extraído del A.D.P.V., E.3.1. Caixa 66, exp, 1141. (Martínez, 1998).

${ }^{5}$ Dato extraído del empadronamiento del siglo XVIII conservado en el Archivo Municipal de Valencia.
} 
comunicación de la ciudad con el extrarradio, como son el camino de Tránsitos (hoy en día avenida de Campanar), la avenida de General Avilés, la pista de Ademuz, o la más actual, avenida Maestro Rodrigo. La puesta en funcionamiento de estas amplias vías ha ido reemplazando poco a poco a las antiguas conexiones de esta parte de la huerta, léase el camino de Paterna, el camino de Campanar, el camino del Pouet, el camino del cementerio, el camino al río, el camino del Molino de la Marquesa o el camino del Molino de San Pablo entre otros. La mayoría de estos itinerarios convivieron con las nuevas vías de tránsito hasta que el progreso urbanístico desatado a partir del siglo XX, desmanteló definitivamente estas antiguas e históricas vías rurales.

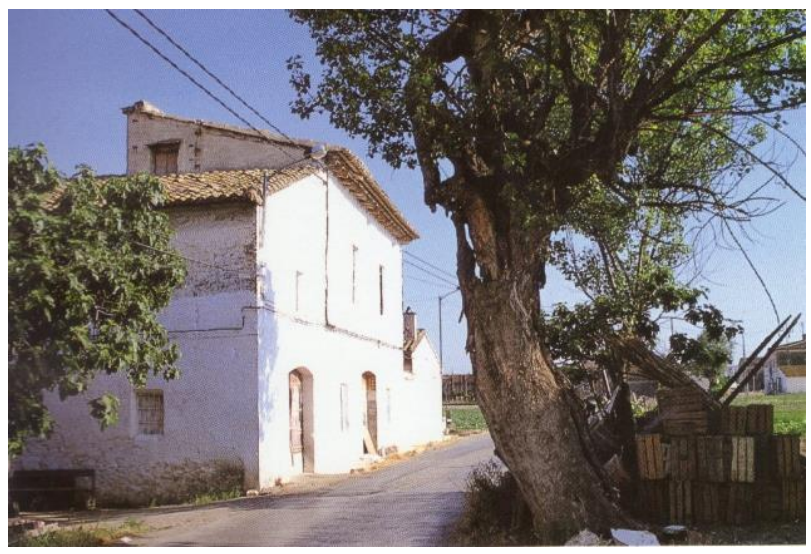

Fig. 5. Camí del Pouet a la altura de la alquería de Puchades con el árbol situado en la orilla a modo de hito característico (Arazo y Jarque, 1988, pp. 69).

\subsection{E1 parcelario.}

Otro elemento imprescindible de la estructura de la huerta es, por descontado, la propia tierra y la división que desde antiguo los distintos pobladores han realizado de la misma para su mejor explotación y beneficio. Podemos encontrarnos con diferentes módulos de división del territorio, como las centuriaciones romanas, la parcelación islámica, la equidistribución parcelaria del repartiment o la microparcelación en la época contemporánea.

Posteriormente a la ocupación del territorio por parte de los romanos, vendrían los árabes, y con ellos un sistema diferente de parcelación ${ }^{6}$. Mientras que las centuriaciones romanas obedecían a grandes extensiones de tierra, perfectamente moduladas, donde se cultivaban el trigo, la vid e inclusive el olivo, y donde la villa de explotación se situaba en el centro de la finca agrícola, en las segundas el criterio será completamente diferente. El diseño de la huerta andalusí tuvo muy en cuenta los elementos naturales y las curvas de nivel del propio terreno, organizando un nuevo sistema parcelario en base a estos criterios de construcción del territorio y a la asignación de los distintos grupos clánicos que se fueron asentando. El territorio se fue estructurando en parcelas desiguales en cuanto a tamaño y forma, siendo muchas de ellas irregulares al tener que adaptarse a los sistemas hidráulicos diseñados y aterrazadas al tener que adaptarse al desnivel del terreno. Esta huerta surcada de un sistema de

\footnotetext{
${ }^{6}$ Como resultado de las investigaciones en torno a las centuriaciones, el propio autor argumenta la falta de coincidencia del trazado de los sistemas hidráulicos y de algunos caminos, como es el caso de la antigua huerta entre Faitanar y Patraix donde el trazado de la propia acequia de Faitanar y, sobre todo, el camí vell de Torrent no son coincidentes con las centuriaciones. (Guinot, 2008, pp. 97-111).
} 
riego planificado y una red de caminos elemental, estaba organizada en unidades de explotación agrícola (Algarra, 2003, pp 61) sobre las que se situaba una alquería.

El parcelario "contemporáneo" que ha llegado hasta nuestros días, fruto del reparto feudal del siglo XIII se caracterizaría por la homogeneidad de parcelas, consecuencia de la distribución equitativa ${ }^{7}$ del territorio. En términos morfológicos se trataba de una estructura rígida en comparación con el parcelario andalusí basado en la "regularidad orgánica" según R. Villaescusa.

\subsection{Hábitats tradicionales de la huerta.}

En cuanto a su arquitectura rural y pre-industrial, ¿qué podemos destacar aparte de ser un extraordinario patrimonio, con una gran carga histórica, que ha sido sepultada junto a su hábitat natural?

Más de un centenar de ingenios hidráulicos, que representaron durante siglos la única industria existente, fueron levantados sobre los cajeros de las ocho acequias que regaban la Huerta de Valencia (Rosselló, 1989) posiblemente desde época bajomedieval. En la zona de Campanar, sobre las acequias de Mestalla y Rascaña, se apostaron un número significativo de molinos, entre los más grandes, el Molino de la Marquesa, San Pablo y el molino de la Esperanza. Por supuesto, todos ellos desaparecidos.

En el cuadro siguiente se indican los artefactos hidráulicos que pertenecen a una de las tres acequias, tramo común o derivaciones, que atraviesan el territorio de Campanar, extraído del libro Les sequies de 1’Horta Nord de Valencia: Mestalla, Rascanya i Tormos (Guinot y Selma, 2005).

Tabla 1. Acequias y molinis existentes.

\begin{tabular}{|c|c|c|}
\hline Acequia & $\begin{array}{l}\text { Tramo de la } \\
\text { acequia }\end{array}$ & Casal \\
\hline \multirow{8}{*}{ MESTALLA } & \multirow{4}{*}{$\begin{array}{l}\text { Tramo común de la } \\
\text { acequia madre }\end{array}$} & Molino Nou o de la Saïdia \\
\hline & & Molino de Pobres \\
\hline & & Molino de la Marquesa \\
\hline & & Molino de l'Esperança o de Palomar \\
\hline & \multirow{4}{*}{ Brazo de Petra } & Molino de Santo Domigo o dels Frares \\
\hline & & Molino de San José o d’Horta \\
\hline & & Molino del Comte o de ponça \\
\hline & & Molino d'Orellana o de Bueso \\
\hline \multirow{3}{*}{ RASCANYA } & \multirow{3}{*}{$\begin{array}{l}\text { Tramo común de la } \\
\text { acequia madre }\end{array}$} & Molino del Sol \\
\hline & & Molino de Sant Pau \\
\hline & & Molino de la Torreta \\
\hline TORMOS & $\begin{array}{l}\text { Tramo común de la } \\
\text { acequia madre }\end{array}$ & Molino de Llovera \\
\hline
\end{tabular}

\footnotetext{
${ }^{7}$ Esta distribución equitativa del territorio se hizo en base a un nuevo sistema métrico y la adopción de un nuevo sistema de unidades de medida superficiales: la fanecada, la cafissada y la jovada
} 
Será éste, el siglo XIX, la época de máximo esplendor de los artefactos hidráulicos como lo demuestra la elevada cantidad de estos elementos censados en la Huerta de Valencia: 112 molinos, la mayor parte de ellos repartidos entre las cuatro grandes acequias: Moncada (27), Favara (24), Mestalla (22) y Rascaña (16). Inevitablemente el siglo XX traería la decadencia de estos artefactos a favor de una industrialización creciente.

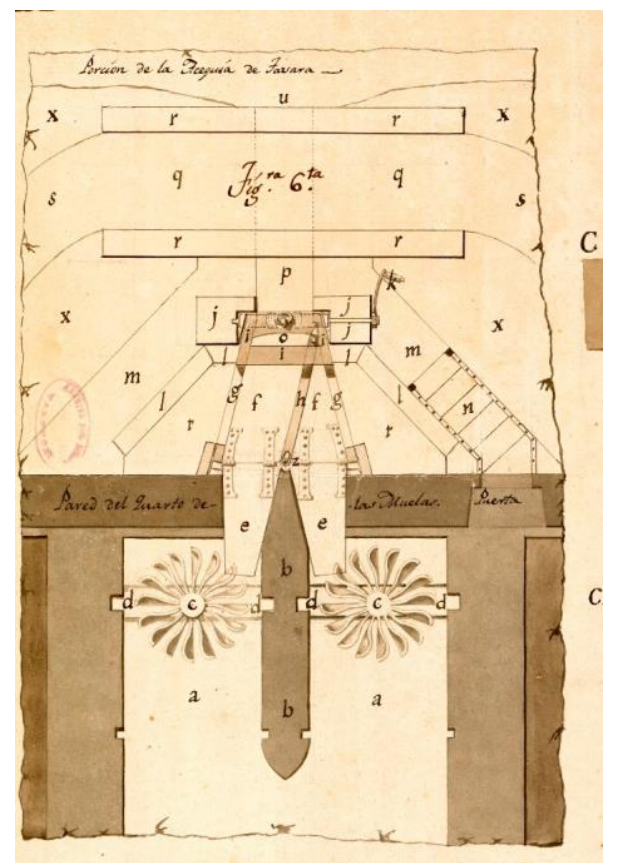

Fig. 6. Detalle del plano geométrico de molino harinero de Don Pascual Chuliá. ARV, Bailía, letra E, exp. 3058, f.2 (nº 166).

Existen diferentes teorías para tratar de establecer una tipología sistemática de los molinos, como la utilizada por Barceló (1988) que establece la dicotomía entre el "molí andalusín" de rueda horizontal y el "molí senyorial" de rueda vertical o la distinción realizada por Glick (1970) entre molinos de ruedas "d'impulsió superior" y "d'impulsió inferior". Parece ser que ninguna de estas teorías recoge la casuística generalizada de los artefactos de la Huerta de Valencia.

Sobre una franja de dos kilómetros de extensión entorno a la ciudad de Valencia se esparcían las alquerías, viviendas y barracas por doquier. En la zona de Campanar, no sólo existía una alta densificación de estas unidades sino que, además, muchas de ellas eran pretéritas, tal y como atestigua Víctor Algarra en los estudios arqueológicos llevados a cabo sobre alquerías del Pouet antes de su demolición, como es el caso de la alquería Barberá.

En resumidas cuentas, son las estructuras características de un paisaje de huerta vivo que hoy es historia, donde sus últimos blasones identificativos agonizan a la espera de su estocada final. Son las consecuencias de un urbanismo que podríamos calificar como inmaduro y egocéntrico, completamente al margen de las estructuras del territorio que ocupa. 


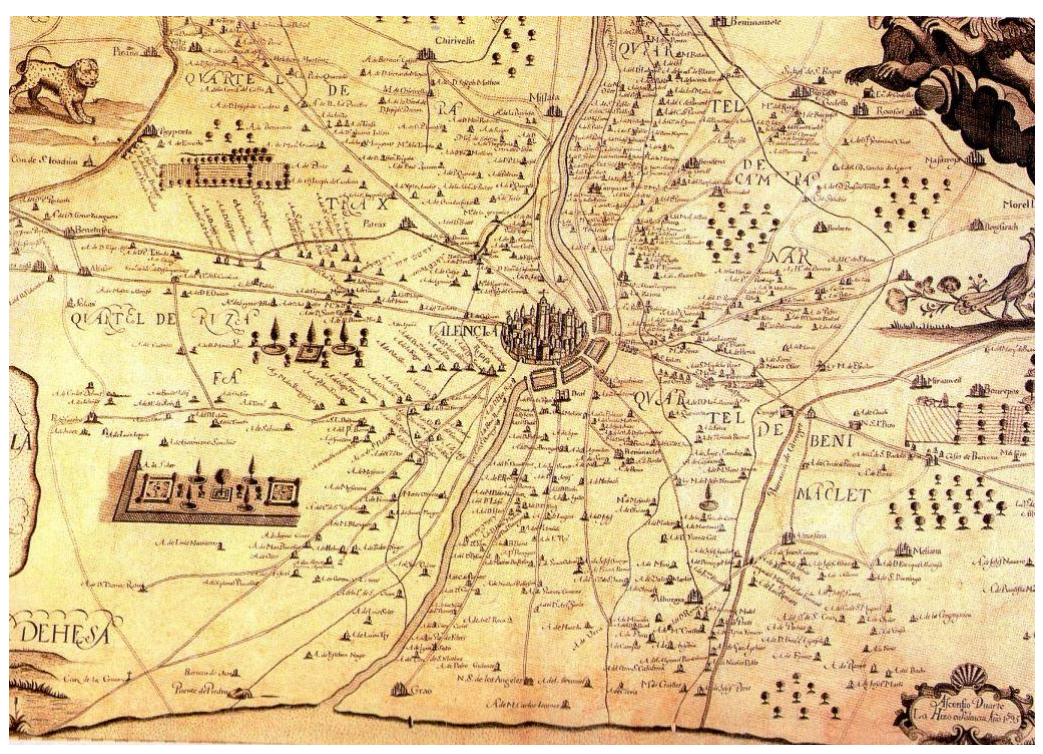

Fig. 7. Plano de Cassaus 1695. (Herrera,1985).

\section{La partida de Dalt y el Molino de Llovera.}

Esta zona llamada también antiguamente partida "de les Basetes" 8 ha llegado prácticamente intacta hasta nuestros días. La protección de una importante área de esta partida y la situación actual de crisis en la construcción ha permitido que la partida se mantenga intacta, por unos años más, fuera del alcance urbanístico. Aunque una parte importante de hectáreas están reservadas para suelo urbanizable y en este momento los terrenos 9 están vendidos a la espera de su futura construcción, aun podemos pasear por campos cultivados, escuchar el correr de las aguas, fijar nuestra vista en sus tradicionales arquitecturas y rememorar la huerta que fue Campanar.

De la partida de Arriba o Dalt, podemos decir, que es el último bastión de lo que fue la huerta de Campanar y en ella se puede localizar elementos tan interesantes como el Molino de Frares, el Molino Nou, el molino de Llovera o la alquería de Lleonart, últimos vestigios de una forma de vida tradicional vinculada a la ciudad. La mayoría de estos emblemas patrimoniales, se encuentran en estado de abandono e incluso ruina, como es el caso denunciado del molino Nou.

\footnotetext{
${ }^{8}$ Llegó a conocérsela por la partida de les basetes haciendo referencia al número tan elevado de balsas que se construyeron para la elaboración del cáñamo. Una vez recolectado tenía que mantenerse en agua durante un tiempo prudencial para su reblandecimiento. Información facilitada por Eduard Pérez Lluch, historiador de Campanar.

${ }^{9}$ En esta zona se localiza "la Gamberra" un grupo de casas, entre ellas la alquería Navarro, y terrenos de cultivo que tienen sus días contados, ya que a día de hoy, estas tierras clasificadas como suelo urbanizable ya están vendidas y vinculadas al proceso urbanizador.
} 


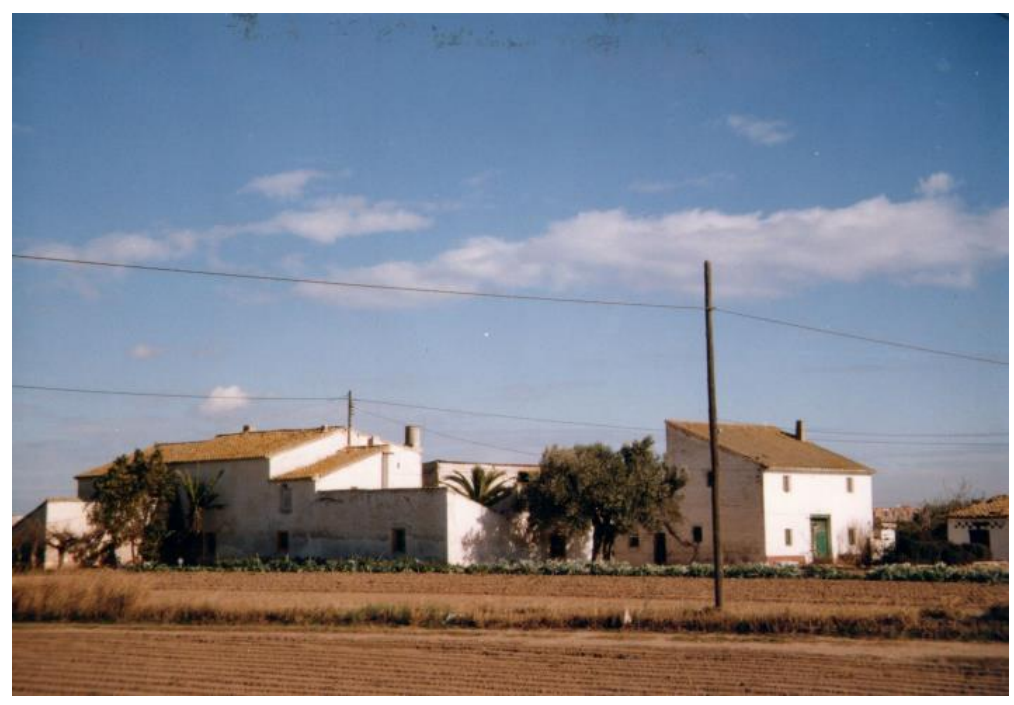

Fig. 8. La Partida del Dalt en la actualidad.

Gracias al Proyecto de Colaboración PROyCO, emprendido hace algunos años y a la disposición desinteresada de sus propietarios, hemos tenido la oportunidad de trabajar en diferentes inmuebles rurales, muchos de ellos no estudiadas con anterioridad, como la alquería del Chufo, la alquería LLeonart, Villa Margarita, casa Nelo Chicopega o la alquería del Roig.

Un ejemplo de la gran riqueza y valor patrimonial que posee la arquitectura tradicional de la Huerta de Valencia queda representado perfectamente en el molino de Llovera, situado en la Partida d'Alt. A continuación aportamos un preámbulo del proyecto realizado por el alumno David Clemente que consitía básicamente en el conocimiento del artefacto hidráulico mediante el levantamiento y profundización en la documentación gráfica y escrita existente sobre el edificio y su entorno. Seguidamente, el alumno desarrollaba un proyecto de rehabilitación con recuperación del Molino para museo y la edificación anexa para alojamientos rurales y una pequeña cafeteria, con el objetivo de revitalizar la zona de huerta donde se enclavaba el conjunto.

Esta formado por un conjunto de edificaciones que conforman el núcleo denominado "Molino de Llobera", situado en medio de la actual huerta de Campanar, en la que se acumulan gran cantidad de elementos significativos de la arquitectura hidráulica de la Huerta de Valencia.

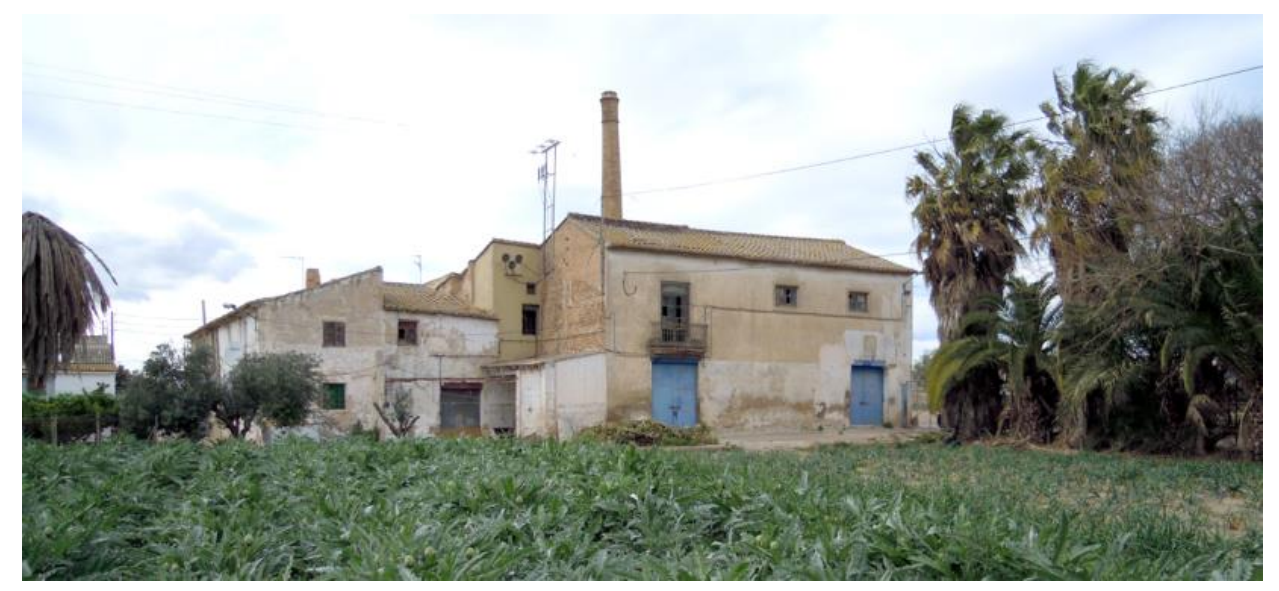

Fig. 9. Vista actual del Molino de Llobera. 
El conjunto del molino está compuesto por un grupo de edificaciones anexionadas entre sí, no visibles desde el propio camino, ya que el molino oculta en la parte opuesta al camino, una pequeña alquería denominada Villa Magdalena medianera con una de las fachadas del molino. La alquería está formada por una vivienda de dos crujías con doble altura y unos pequeños almacenes agrícolas de una altura y una crujía. Junto a uno de los cuerpos de la alquería se sitúa una vivienda de doble altura, la cual comparte estructura con esta. Anexionado a la parte oeste de esta vivienda se encuentra un pequeño recinto cubierto a un agua que se utiliza como almacén de herramienta de labranza. Todos los edificios están orientados entorno al molino y forman con este un gran patio que hoy en día está ocupado por unas naves industriales, las cuales impiden una visión del conjunto desde el propio camino.

En cuanto al molino como edificio en sí; destaca su volumen condicionado a su ubicación, ya que ocupa una pequeña parte del camino, estrechándose un poco, dando la impresión al espectador o viandante de ser un edificio defensivo, muy delimitador de la propiedad, debido en parte por la altura de la cubierta y a su escasa fenestración.

Su geometría aparentemente parece responder a una construcción de planta ortogonal, a mitad de camino entre una construcción con fines industriales, por su escasez de fenestración, y una casa señorial del siglo XIX por el recercado de los huecos de la planta superior y el balcón. El la actualidad el aspecto del edificio es de total abandono pero se mantiene bien conservado, a pesar del deterioro de algunos de sus revestimientos exteriores.

El interior del molino se conserva en buen estado, aunque no quedan restos de la maquinaria de molienda. Apenas quedan algunos cabirones de madera incrustados por un extremo en los muros dando indicios de lo que hubo alguna vez instalado.

Atendiendo a la lectura de los diferentes elementos y vestigios existentes en el molino, se ha posibilitado la realización de la hipótesis de su evolución histórica. Desde sus orígenes, el edificio respondía a dos usos prioritarios: vivienda y molino de grano. Es importante comentar la integración de la vida familiar en el proceso productivo ya que los habitantes eran pieza básica en la fuerza de trabajo del molino.

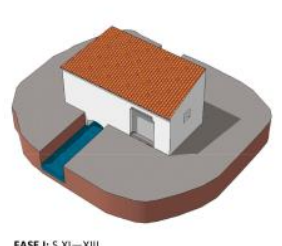

FASE: : S.XI-XIII

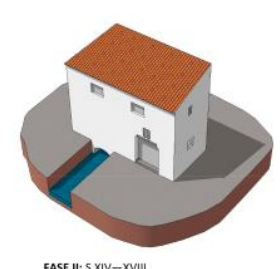

FASE II: SXIV-XVIII

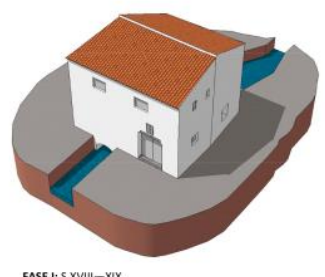

FASE : : SXVIII-XIX

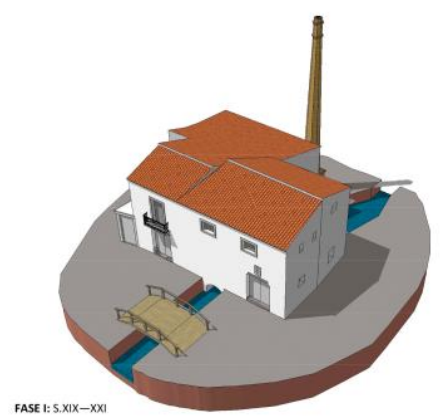

FASE : : $:$.XIX $-\mathrm{xx|}$

Fig. 10. Infografía sobre la posible evolución historica del Molino de Llovera.

Gracias a la documentación consultada, así como por el análisis del levantamiento planimétrico es muy probable que en un principio el molino existiera como una construcción aislada, de una sola planta, características propias de los molinos de origen árabe. 
Más tarde evolucionó alcanzando dos plantas, ya en época bajomedieval, para dar cabida a todas las necesidades de una producción mayor. A partir del siglo XVIII el edificio se amplia por la parte posterior al acceso, eliminando el muro en planta baja para mayor diafanidad obligando a la inserción de un pilar central con dos vigas que soportan el muro de planta superior. En esta época se instalan dos muelas lo que podría lleva a una reforma de los cárcavos.

Durante el siglo XIX se construye un edificio anexo con la misma tipología pero con menor altura libre en planta baja, que se destina al almacenamiento del grano y la harina y en la planta superior para vivienda familiar del molinero. El establecimiento del molino funcionaba de forma independiente a la de la casa.

Según la bibliografía consultada y la documentación que obra en el Ayuntamiento de Valencia, a finales del siglo XIX sufrió una reforma profunda de espacios y funciones. La planta superior del molino se desmanteló para ampliar la casa, ocupando así toda la planta superior para un uso residencial. Esto obligó a conectar los edificios entre sí en la planta superior mediante una apertura de hueco en muro. La planta inferior tenia un uso industrial y a comienzos del S.XX se erigió una chimenea para la nueva maquinaria a vapor la cual que generaba mayor fuerza motriz.
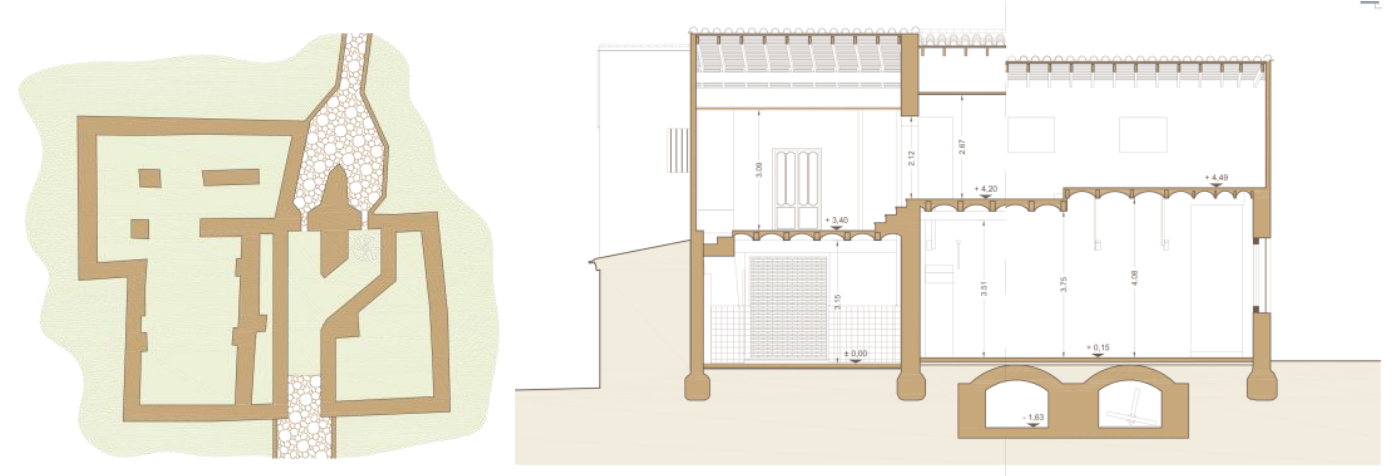

Fig. 11. Plano en planta y sección del molino de Llobera. Estado actual.

La nueva vivienda ya no era habitada por la familia del molinero, si no por el dueño o señor del molino. La vivienda pasó a tener un carácter más señorial y de segunda residencia, lo cual era muy habitual en época estival.

La antigua sala de muelas se desmanteló a mediados del s. XX y se ha sido utilizada hasta nuestros días como almacén agrícola. La casa actualmente está deshabitada y tiene un uso de almacén en planta baja, así como de albergue para un transformador de reciente construcción.

La planta superior está en desuso aunque ha sido compartimentada en época reciente para ser usada en parte por las naves industriales anexas al edificio cuya propiedad coincide con la del molino. 


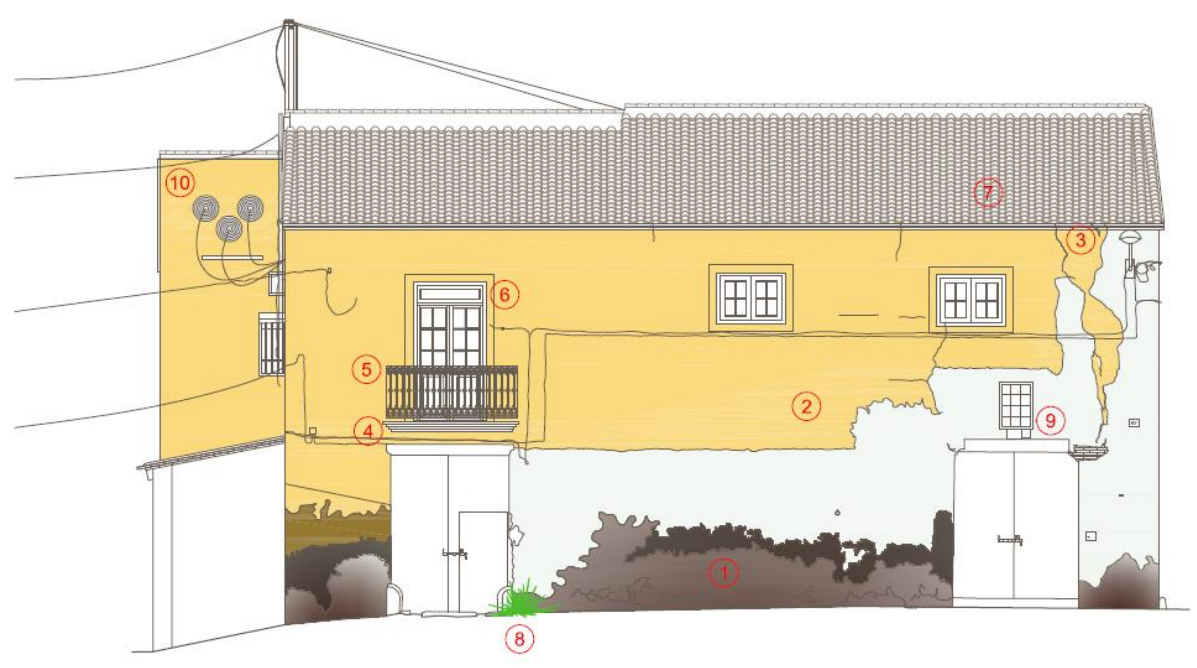

Fig. 12. Mapeado de patologías de la fachada principal.

\section{Conclusiones}

Dado el escenario futuro que plantea el crecimiento continuado de la metropoli sobre su huerta, pensamos que el conocimiento y puesta en valor de las estructuras de su territorio, así como de sus elementos y arquitecturas tradicionales, mediante metodologías de trabajo como la que llevamos a cabo en el Proyecto de Colaboración PROyCO, donde hacemos participes a alumnos, propietarios, vecinos, personas comprometidas con el patrimonio y responsables de las corporaciones -Ayuntamientos, Universidad y Asociaciones de vecinos-, puede ser una herramienta de discernimiento a la hora de considerar nuevas estrategias de intervención sobre los bordes ampliados de la ciudad de Valencia, y por extrapolación, de cualquier centro urbano coetáneo.

\section{Referencias}

Arízaga Bolomburu, B. (2002): La imagen de la ciudad medieval. La recuperación del paisaje urbano. Servicio de Publicaciones de la Universidad de Cantabria, Santander.

Algarra, V.; Ruiz, E. (1998): Informe preliminar de la intervención arqueológica realizada en las alquerias de barberá y Benlloch, partida del Pouet, Campanar, Valencia.

Borrul , F. X., (1851): Tratado de la distribución de las aguas del rio Turia y del Tribunal de los Acequieros de la Huerta de Valencia. T. VIII, Imprenta Benito Monfort. Valencia.

Glick, T.F. (1970): Irrigation and society in Medieval Valencia. Cambridge, Mass. Harvard University Press.

Glick, T.F. (2000): Els molins hidráulics valencians: Tecnología, historia i context social. Valencia, Institució Alfons el Magnánim. 
González Villaescusa, R. (1996): "Paisaje agrario, regadío y parcelarios en la huerta de Valencia, nuevos planteamientos desde el análisis morfológico", II Coloquio Historia y Medio Físico. Agricultura y regadío en al-Andalus. Almería.

González Villaescusa, R. (2007): "la huerta cuando no lo era. La configuración histórica del territorio de Valencia", en Hermosilla, J., (dir), El Patrimonio hidráulico del Bajo Turia: l'Horta de Valéncia. Dirección General del Patrimonio Cultural Valenciano, Generalitat Va-lenciana.

Guinot, E. (2007): "Una historia de la Huerta de Valencia" en Hermosilla, J. (dir.), El patrimonio bidráulico del Bajo Turia: l'Horta de Valencia. Dirección General de Patrimonio Cultural Valenciano. Generalitat Valenciana.

Guinot, E. (2008): "El paisaje de la huerta de Valencia. Elementos de interpretación de su morfología espacial de origen medieval". Historia de la Ciudad V. Tradición y progreso. COACV. Valencia.

Guinot E., Selma S. (2005): Les séquies de l'horta Nord de València: Mestalla, Rascanya i Tormos. Camins d'aigua, el patrimonio bidràulic valencià. Generalitat Valenciana, Consellería d’Agricultura, Pesca i Alimentació.

Jaubert De Passá, F. J. (1844): Canales de riego de Cataluña y Reino de Valencia, leyes y costumbres que los rigen, reglamentos y ordenanzas de sus principales acequias, T. I y II. València. Imprenta de B. Monfort.

Mangue Alférez, I. (2001): Marxalenes: De alquería islámica a barrio de la ciudad de Valencia. Ajuntament de València.

Martínez Sanmartín, L.P. (1998): "Paisajes medievales: el molí dels Frares y la huerta de Campanar" en Curso de conservación y restauración del patrimonio histórico valenciano. El Moli dels Frares y el mural de la batalla de Salses, UIMP.

Rosselló i Verger, V. Ma . (1989):“Els molins d'aigua de l'horta de València” en Los paisajes del agua. Universitat de Valencia.

Rosselló i Verger, V. Mª (dir) (1990): Les vistes valencianes d'Anthonie van den Wijngaerde. Valencia.

Teixidor de Otto, $\mathrm{M}^{\mathrm{a}} \mathrm{J}$. (1982): València, la construcción d'una ciutat, Col. Politécnica 2. Diputació Provincial de València.

Tello, E. (1999): "La formación histórica de los paisajes agrarios mediterráneos: una aproximación coevolutiva", Historia Agraria, 19: 195-212. 